\title{
Water consumption: Emotionally produced facilitation or suppression?
}

\author{
SEYMOUR LEVINE ${ }^{2}$ \\ STANFORD UNIVERSITY SCHOOL OF MEDICINE
}

\begin{abstract}
Four groups of rats were tested for water consumption following exposure to novel or noxious stimuli. Facilitation of drinking was obtained if the Ss were given four novel or shock experiences prior to drinking whereas suppression was obtained if only one novel or noxious experience preceeded the drinking test.

Introduetion

Recently in this Journal, Moyer (1965) reported that emotionality produced by $15 \mathrm{~min}$. exposure to a strange environment with or without shock caused an initial suppression of water consumption measured in the home cage, but that repeated exposure to the shock caused a subsequent facilitation. Moyer's conclusions were that "Whether a given experimental manipulation results in depression or facilitation of the consummatory response seems to depend upon the Ss past experience." This present experiment presents evidence, however, which indicates that suppression or facilitation is also dependent upon the immediate experience prior to the measure of consummatory behavior.
\end{abstract}

\section{Method}

The Ss were 40 naive male albino rats purchased from the Holtzman Co., Madison, Wisconsin. They were between 80 and 100 days of age at the start of the experiment. The apparatus consisted of: (1) Individual cages in which Ss were confined for $10 \mathrm{~min}$. daily to measure the amount of water consumed. (The inside dimensions of the cage were 8 in $x 7$ in $\times 8$ in; the floor, top and front of the cages were made of hardware cloth and the rear wall was solid galvanized iron; the top and sides were covered with cardboard.); and (2) A shocking device connected to a grid. (Shock was delivered in a box of similar dimensions. The top and sides of this box were constructed of clear plexiglas; the front and back of stainless steel. The shock source was a Grason Stadler Generator Model No. 1064GS.).

Ten days prior to the beginning of the experiment proper, the Ss were handled for about $5 \mathrm{~min}$. per day. During this period a schedule of $12 \mathrm{hr}$. of water deprivation and $24 \mathrm{hr}$. of food deprivation was established. Following this initial period of habituation, a 14-day period ensued during which measurements were taken daily in the drinking cage of the amount of water consumed by each $\mathrm{S}$ during a 10-min. period. Forty-five min. prior to drinking, each $\mathrm{S}$ was given $5 \mathrm{gm}$ of chow without water; the food was eaten in abut $15 \mathrm{~min}$. Following $10 \mathrm{~min}$. of drinking, each $\mathrm{S}$ was returned to the home cage and after 15 min. had elapsed, each $\mathrm{S}$ was given the remainder of the $10 \mathrm{gm}$ daily food ration. On the last day of the train- ing period the Ss were divided into four groups comprised of $10 \mathrm{Ss}$ each. The Ss within each group were equated for amounts consumed during the control period. This procedure was used to insure equal water consumption prior to the experimental treatment.

The four groups consisted of two novelty groups and two shock groups. The novelty groups were placed in the box in the absence of shock. The shock groups received $.80 \mathrm{ma}$ of shock. For the first novelty group $\left(\mathrm{N}_{4}\right)$ and shock group $\left(\mathrm{S}_{4}\right)$, each $\mathrm{S}$ received four trials each of $20 \mathrm{sec}$. duration with an intertrial interval of about $10 \mathrm{~min}$. Thus the novelty animals were placed in the box for $20 \mathrm{sec}$. without shock, and shock animals were placed in the box and given $20 \mathrm{sec}$. of continuous scrambled shock. On the last trial of each day of the 5-day testing period, the $\mathrm{S}$ was immediately placed in the drinking cage. The two additional groups were placed in the box on only one occasion prior to drinking and thus were given only one novelty experience $\left(\mathrm{N}_{1}\right)$ or one shock experience $\left(S_{1}\right)$ on each day of the 5 -day test period.

\section{Results}

Results presented in Fig. 1 indicate that both suppression and facilitation are obtained. One critical variable appears to be the number of prior experiences with emotionally arousing stimuli. Both the $\mathrm{N}_{4}$ and $\mathrm{S}_{4}$ groups showed significant facilitation beginning with the first test day and continuing throughout the five subsequent test periods, whereas the $\mathrm{N}_{1}$ and $\mathrm{S}_{1}$ groups showed suppression throughout the five days of testing. It should be noted that although there were no significant differences between the novelty and the shock groups in facilitation, there was a significant difference $(p<.01)$ in suppression with shock as opposed to novelty following one experience per day. A trend analysis indicated that water consumption continued to increase in the $\mathrm{N}_{4}$ and $\mathrm{S}_{4}$ groups over the 5-day period, and in contrast to Moyer, there was also a continued suppression in water consumption decreasing over the 5-day period for the $\mathrm{N}_{1}$ and $\mathrm{S}_{1}$ groups.

\section{Diseussion}

Insofar as the procedures used in this experiment differ in many respects from that reported by Moyer, it is difficult to make a direct comparison between this study and the Moyer study. In this experiment like the Amsel \& Maltzman (1950) experiment, the animals had been handled extensively prior to introduction to the experimental procedures. Using essentially the Amsel and Maltzman design we are able to replicate the in- 


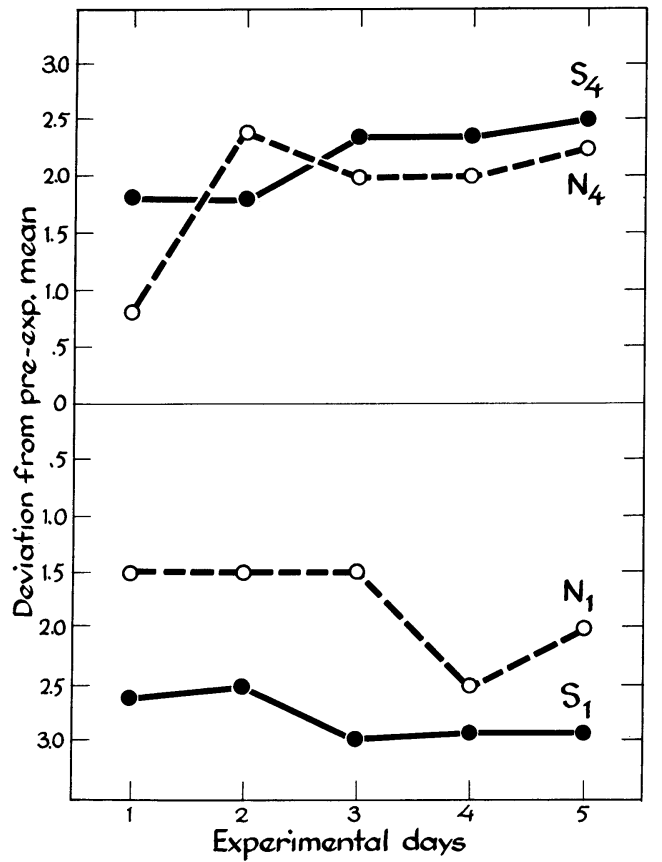

Fig. 1.. Water consumption expressed in terms of $\mathrm{ml}$ of change from the mean score for that group on pre-experimental days.

crement of facilitation in consummatory response following the experience with noxious stimuli. However, in the Levine (1958) study where depression of consummatory behavior was reported, all of the testing prior to the introduction of the experimental procedures was done in the home cage. Thus on the experimental day the animals were handled for the first time. It would appear then that among the variables determining whether facilitation or suppression in water consumption will occur are (1) the amount of prior handling before exposure to the novel or noxious stimuli, and (2) the amount of exposure to emotionally provoking stimuli prior to the measure of consummatory behavior.

It is not surprising that exposure to the box should have essentially the same effects as that of shock. There is no question that the physiological responses to novel environments are initially similar if not identical to those of exposure to shock (Foriter, 1958; Levine \& Treiman, 1964). Recently in an unpublished study (Levine, Haltmeyer \& Denenberg) it was demonstrated that after four days of exposure to an open field animals still exhibited a marked and significant increase in adrenal corticosterone. Thus habituation to novel stimuli is by no means a rapid process and tha; the internal cues produced by novel stimuli are sufficiently similar to those elicited by shock to result in essentially the same effects on consummatory behavior. The question does remain, however, as to why a single experience with novel or noxious stimuli is sufficient to cause suppression whereas multiple experiences cause a facilitation.

Spence (1956) has stated "the hypothetical emotional response $\left(r_{\mathrm{e}}\right)$ could exhibit adaptation to a continued presentation of the noxious stimulus. Accordingly, after a series of stimulus presentations, the level of drive produced on the occasion of any trial should be lower if such adaptation trial had not been given." It is possible, therefore, that the level of drive resulting from four shock trials instead of being increased is reduced so that the interfering responses associated with intense emotional responses are likewise reduced, permitting summation of drive to be manifest. However, in the situation where only one shock or one novel experience is given, presumably little or no adaptation has occurred and consequently the level of $D$ should be high and interfering responses should be evident. It is also possible to evoke a physiological explanation involving the role of vasopressin and ACTH in stress, etc. to account for these data. The facts do remain that depending upon the training experience and the test experience, both facilitation and suppression of drinking are possible.

\section{References}

Moyer, K. E. Effect of experience with emotion provoking stimuli on water consumption in the rat. Psychon. Sci., 1965, 2, 251-252.

Amsel, A., \& Maltzman, I. The effect upon generalized drive strength of emotionality as inferred from the level of consummatory response. J. exp. Psychol., 1950, 40, 563-569.

Levine, $\mathbf{S}$. Noxious stimulation in infant and adult rats and consummatory behavior. J. comp.physiol. Psychol., 1958, 51, 230-233.

Fortier, C. Sensitivity of the plasma free corticosteroid response to environmental change in the rat. Arch. int. Physiol. Biochem., $1958,66,672-673$.

Levine, S., \& Treiman, D. M. Differential plasma corticosterone response to stress in four inbred strains of mice. Endocrin., $1964,75,142-144$.

Spence, K. W. Behavior theory and conditioning. New Haven: Yale University Press, 1956. P. 180.

\section{Notes}

1. This research was supported by NIH Grant MH 07435

2. Research Career Development Award 5-K3-19,936-02. 